\title{
Stenting of Unprotected Left Main Coronary Artery Stenosis: Immediate out comes in NICVD our Initial Experience
}

\author{
KAJAL KUMAR KARMAKAR ${ }^{1}$, MIR JAMALUDDIN ${ }^{1}$, IBRAHIM KHALIL ${ }^{1}$, BAZLUR RASHID ${ }^{1}$, \\ RAKIBUL ISLAM LITU ${ }^{2}$, HUMAYUN KABIR ${ }^{1}$, A.H.K CHOWDHURY ${ }^{1}$,A.A.S MAJUMDER ${ }^{1}$, \\ CHANDAN KUMAR SHAHA ${ }^{3}$, ABUL KHAIR ${ }^{1}$, ZAHID HASAN ${ }^{1}$, SHAHIN KABIR ${ }^{1}$
}

${ }^{1}$ Department of Cardiology, National Institute of Cardiovascular Disease (NICVD), Dhaka, ${ }^{2}$ Department of Cardiology, Uttara Adhunik Medical College, Dhaka, ${ }^{3}$ Department of Cardiology, Gazipur Medical College, Gazipur

Address of Correspondence: Dr. Kajal Kumar Karmakar, Associate Professor, Dept. of Cardiology, National Institute of Cardiovascular Disease (NICVD), Dhaka, E-mail: drkajal71@gmail.com

\begin{abstract}
:
This study aims to describe the initial experiences and immediate outcomes of percutaneous coronary intervention (PCI) in patients with significant left main coronary artery disease with normal LV function in National Institute of Cardiovascular Diseases (NICVD), Dhaka. Left main coronary artery disease is regarded as an absolute contraindication for coronary angioplasty. Recently several reports on protected or unprotected LMCA stenting or both suggested the possibility of percutaneous intervention for this prohibited area. The study was conducted in National Institute of Cardiovascular diseases \& Hospital, Dhaka, Bangladesh. Participants of the study were 100 patients with a diagnosis of critical left main coronary artery disease. Information was collected on their demographic characteristics and clinical history. Relevant physical examination and laboratory investigation were performed. Percutaneous transluminal coronary angioplasty (PTCA) with stent implantation were done in the left main coronary artery and other culprit vessel where required. They were followed up thoroughly during the hospital stay. The study subjects were from 35 to 70 years old. 70 male and 30 female were included in this study. According to the clinical history, 12 lead surface ECG reading and cardiac enzyme analysis $40 \%$ patient was diagnosed as unstable angina, $40 \%$ presented with chronic stable angina and rest of them presented with old myocardial infarction. Among the study population critically isolated LM disease were 30\%, critical left main with other vessels disease were $70 \%$. The pattern of LM disease involvement were osteal $40 \%$, mid shaft $10 \%$, distal bifurcation $30 \%$, entire LM involving bifurcation 20\%. Procedural success rate was $100 \%$. No patient faced major advance cardiac events (MACE) during hospital stay. Stenting of unprotected LM coronary artery stenosis may be safe effective alternative to CABG in carefully selected patients with normal $L V$ function. Further studies in larger population of this group are needed to assess late out comes.
\end{abstract}

Introduction:

Significant unprotected left main coronary artery (ULMCA) disease occurs in 5-7\% of patients undergoing coronary angioplasty ${ }^{1,2}$ and patients with ULMCA disease treated medically have a 3 years mortality rate of $50 \%{ }^{3,4}$. Several studies have shown a significant benefit following the treatment of left main (LM) stenosis with coronary bypass grafting (CABG) compared with medical treatment ${ }^{5-}$ 8 . Until recently CABG has been the gold standard therapy for LM disease. Stenting of unprotected LMCA stenosis has been attempted as a therapeutic option in selected patients with prohibitive surgical risk, usually as a result of non cardiac co-morbidities ${ }^{9-11}$. A few cases of stenting of unprotected LMCA stenosis have been reported in bailout situations ${ }^{12-14}$. Thus far elective stenting in patients with unprotected LMCA stenosis has been regarded as a contraindication, mostly due to potential fatal out come from sub acute stent thrombosis. However in the past few years there have been significant improvements in stent implantation techniques ${ }^{15}$, stent technology and post stent antithrombotic agent ${ }^{16}$ have allowed evaluation of the role of PCI for LM disease. Recent studies have focused on the safety and efficacy of stenting the LMCA to determine whether it does provide a true alternative to CABG.

Though CABG is the gold standard treatment in case of critical LM disease, recent guidelines have reevaluated the indication of PCI, suggesting LM PCI can be the safe option in comparison to CABG in selected patient group where high surgical risk \& co-morbid conditions accompanying the patient. More over considering the health economics in developing countries like Bangladesh where resources, manpower, skill personals are limited in cardiac surgery side. So to reduce hospital cost \& stay PCI to LM can be the true alternative to CABG. Till today 
no data is available as to measure the safety \& efficacy of stenting in UPLM disease in our country. So we have taken the imitative $1^{\text {st }}$ time in a small scale to measure the immediate outcome of PCI in UPLM disease. The objective of this study is to determine whether stenting of UPLM coronary stenoses is safe in selected patient and thus may provide an alternative to CABG.

\section{Methods:}

From January 2012 to April 2014, a total of 100 consecutive patients with significant unprotected LMCA stenoses who declined CABG were treated with stent implantation in the department of cardiology, NICVD, Dhaka, Bangladesh.

Inclusion criteria: Patient with unstable angina, chronic stable angina \& old myocardial infarction who had significant left main coronary artery disease $(\geq 50 \%$ diameter stenoses of left main artery) with or without other coronary involvement.

\section{Exclusion criteria:}

1) Contra indication to aspirin or clopidogrel.

2) Patient with surgery indicated for valvular heart disease.

3) Patient with co morbidities such as malignancy, CRF (CCR $<30 \mathrm{ml} / \mathrm{min}$ ) coagulation or bleeding disorder which make a PCI unadvisable.

4) Reduced LV function ( $\mathrm{LVEF}<40 \%$ )

5) Patient refused LM PCI.

In addition to significant LMCA stenosis, significant narrowing of other coronary arteries were also stented at the same time. All patients gave written informed consent to participate in this study. Coronary angiogram was done according to the criteria of ESC/ACC/AHA guidelines. Base line clinical data including demographic characteristics, clinical history \& risk factors were recorded on the case report form. Relevant physical examinations were performed in all patients. ECG, Echocardiography, blood sugar level, serum creatinine, BT, CT, HBV, HIV, HCV \& VDRL reports were obtained in all patients. After diagnosing the critical stenosis in left main with or without stenosis in the other vessels PCI was performed in left main coronary artery and other vessel where required. Stent implantation was performed electively in all patient. An intra aortic balloon pump was prepared for emergency cardiopulmonary support, if needed but was not inserted prophylactically. Pre dilatation before stent implantation was performed with undersized, conventional angioplasty balloons. The stent was then deployed by inflating the stent delivery balloon at nominal pressure. After deployment of the stent, stented segment were further dilated with high pressure balloon inflation, to achieve angiographic optimization.

The balloon inflation were brief ( $<30$ sec) and multiple $(\geq 3)$ to avoid prolonged ischemia \& ischemia related complications. The size of the stent was $\geq 3.5 \mathrm{~mm}$ in all LM lesions. The lesions at the ostium or shaft without involvement of the distal bifurcation comprised $70 \%$ of the lesion. The stents used to treat all LMCA lesion was drug eluting stent. During the procedure, patients received a 10,000-U bolus of heparin with a repeat bolus of $5000 \mathrm{U}$ every 30 minutes to maintain a activated clotting time of $>300$ sec. All patient were kept in the coronary care unit (CCU) for 24 hour and later shifted to coronary step down unit before discharge. All patients received loading dose of 300mg aspirin \& 600mg clopidogrel before the procedure. After the procedure all patients were maintained with 150mg aspirin \& 75mg of clopidogrel per day for at least one year. Other pharmacological treatment (eg statin, angiotensin converting enzyme inhibitors, beta blockers) were recommended based on current practice. Primary end point was in-hospital mortality, Q wave MI \& repeat revascularizations.

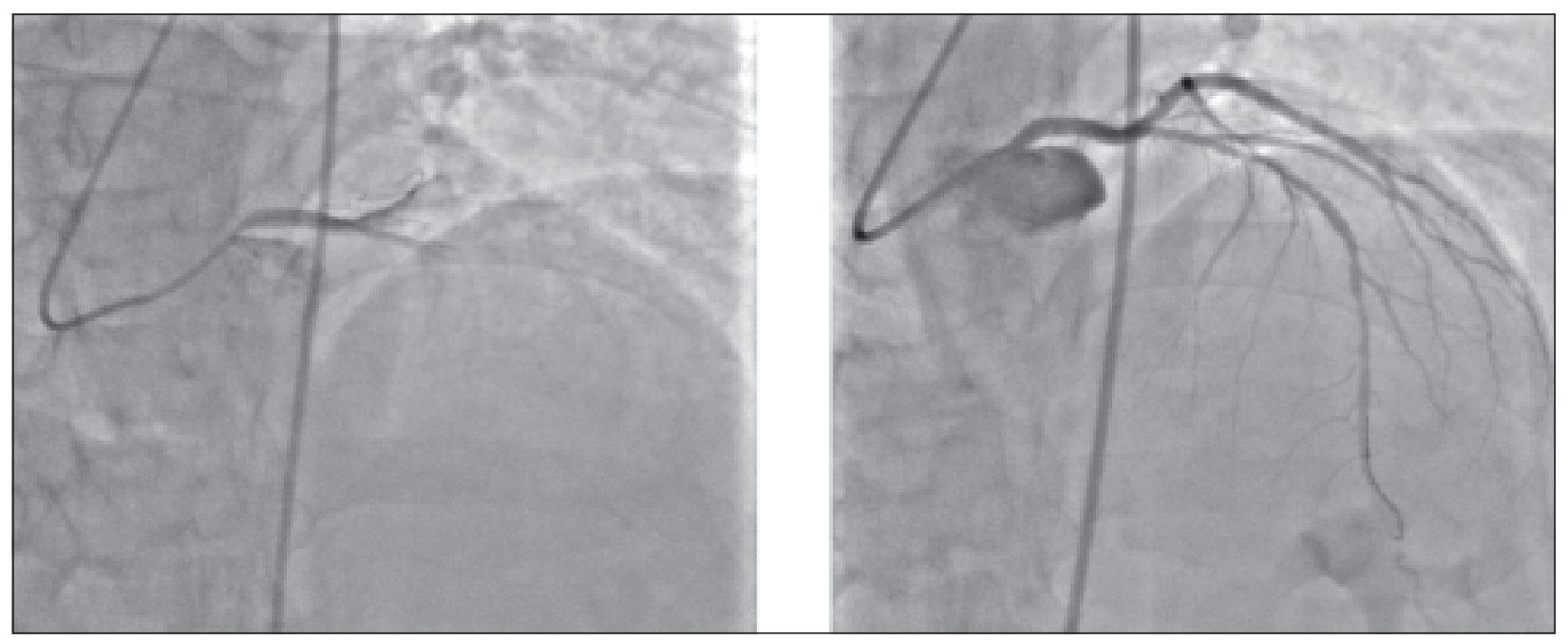

Fig.-1: Patient with LM osteal stenosis before and after PCI 

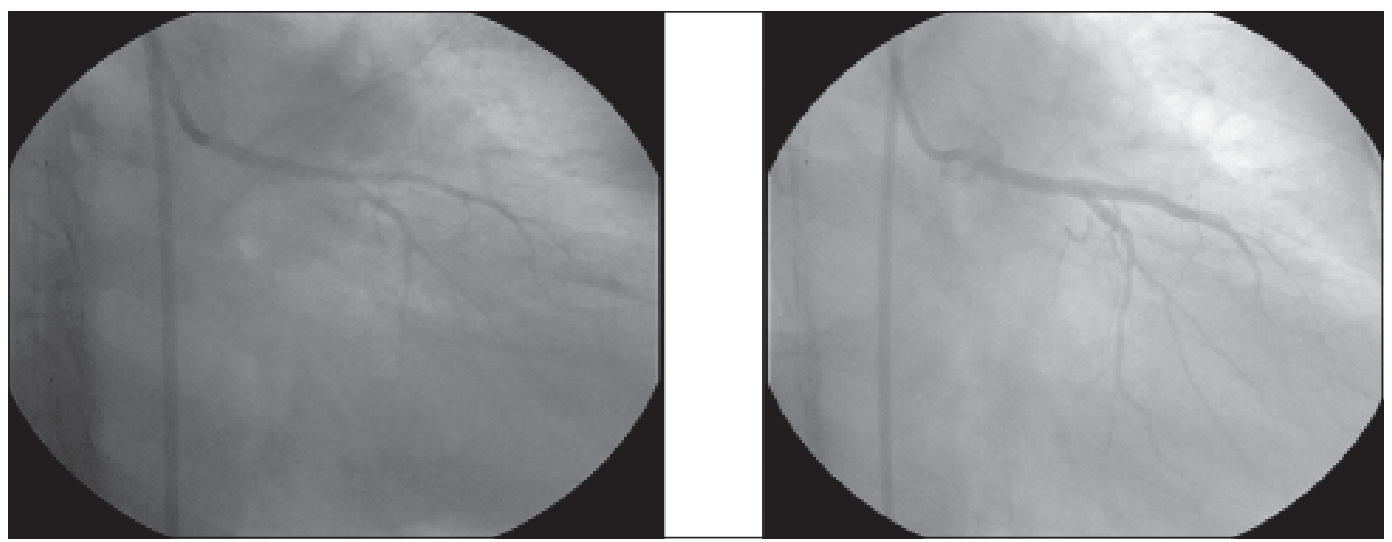

Fig.-2: Patient with LM distal stenosis with bifurcation involvement before and after PCI

\section{Results:}

A total of 100 patients with coronary artery disease who underwent coronary angiogram and found critical stenosis in LM coronary artery with or without involvement of other three vessels and underwent reperfusion therapy with PTCA were studied. Their mean age was $53.1 \pm 12.6$ years. The most common age group was $51-60$ years $(37.5 \%) 30 \%$ of them were female and $70 \%$ were male. Cigarette smoking was the most common risk factor, found in 50(50\%) of study patients. Other risk factors were diabetes mellitus in 30(30\%) patients, Hypertension in $40(40 \%)$ patients and dyslipidemia in 24(24\%) patients. A family history of coronary artery disease (CAD) was found in $20 \%$ of patients, $20 \%$ had a history of a myocardial infarction, and none had undergone a previous PCI and none had heart failure.

\section{Table-I}

Demographic characteristics and risk factor profile of study population. $(\mathrm{n}=100)$

\begin{tabular}{ll}
\hline Age distribution & $35-70$ yrs \\
Mean age & $53.10 \pm 12.56$ \\
Sex & \\
$\quad$ Women & $30(30 \%)$ \\
Men & $70(70 \%)$ \\
Family history of CAD & \\
$\quad$ Present & $20(20 \%)$ \\
Absent & $80(80 \%)$ \\
Diabetes & \\
$\quad$ Present & $30(30 \%)$ \\
Absent & $70(70 \%)$ \\
Hypertension & \\
$\quad$ Present & \\
Absent & $40(40 \%)$ \\
Smoking & $60(60 \%)$ \\
Smoker & \\
$\quad$ Nonsmoker & \\
Dyslipidemia & \\
Present & $50(50 \%)$ \\
Absent & $50(50 \%)$ \\
\hline
\end{tabular}

The patients were suffering from unstable angina (40\%), Chronic stable angina (40\%), and old Mocardial infarction (10\%). Amongst the patients who were suffering from old MI, 80\% had an anterior MI and 20\% had an Inferior MI.

Table-II

Clinical diagnoses $(n=100)$

\begin{tabular}{ll}
\hline Unstable Angina & 40 \\
Chronic stable angina & 40 \\
Old MI (Anterior) & 16 \\
Old MI (Inferior) & 4 \\
\hline
\end{tabular}

After the coronary angiogram diagnoses of isolated critical left main coronary artery stenosis were found in 30 patients (30\%) and critical left main with other coronary artery disease was found in 70 subjects (70\%). 20(20\%) patients had LAD stenosis with the critical stenosis of left main artery, 30(30\%) patients had LCX involvement and 20(20\%) had RCA involvement with the critical stenosis of left main coronary artery.

\section{Table-III}

Coronary angiogram $(C A G)$ diagnoses $(n=100)$

\begin{tabular}{lc}
\hline Critical isolated LM disease & $30(30 \%)$ \\
Critical LM with other vessels disease & $70(70 \%)$ \\
Critical LM with LAD & $20(20 \%)$ \\
Critical LM with LCX & $30(30 \%)$ \\
Critical LM with RCA & $20(20 \%)$ \\
Pattern of LM involvement & \\
Osteal & $40(40 \%)$ \\
Mid shaft & $10(10 \%)$ \\
Distal bifurcation & $30(30 \%)$ \\
Entire LM involving bifurcation & $20(20 \%)$ \\
\hline
\end{tabular}

We also try to classify different position of involvement of the left main artery disease. Osteal involvement was 
found in 40(40\%) patients, $10(10 \%)$ had mid shaft, 30(30\%) had distal bifurcation. 20(20\%) had entire left main disease with involvement of the bifurcation.

Table-III

Procedure details $(n=100)$

\begin{tabular}{ll}
\hline Osteal single stent & 40 \\
Osteal plus mid shaft Single stent & 10 \\
Entire Left main single stent & 20 \\
Distal bifurcation & \\
$\quad$ Single stent & 20 \\
$\quad$ Double stent & 10 \\
\hline
\end{tabular}

PTCA was done by using drug eluting stents. In most of the cases (90\%) a single stent was sufficient. 10\% needed double stents to cover the entire length of the left main coronary artery. All osteal, osteal with mid shaft, entire left main lesions were covered with a single stent. 20 of the patients with distal bifurcation involvement needed single stent but 10 patients with distal bifurcation needed double stent.

\section{Discussion:}

The LMCA is of importance as it supplies approximately two-thirds of the blood to the heart and almost $100 \%$ of the blood flow to the left ventricle. As a result severe LMCA disease will reduce flow in a large portion of the myocardium placing the patient at a risk for life threatening events of LV dysfunction and arrhythmia ${ }^{17}$. The LMCA differs from the other coronary arteries by its relatively greater elastic tissue content which can explain elastic recoil and high restenosis rate following balloon angioplasty ${ }^{18}$. Atherosclerotic lesions tend to form at specific regions of the coronary vasculature where flow is disturbed, particularly in area of low shear stress ${ }^{19}$. In the LMCA bifurcation, intimal atherosclerosis is accelerated primarily in area of low shear stress in the lateral well close to the LAD \& LCX bifurcation. Thus the carena is frequently free of disease and this can explain the reason why single stent strategy (Provisional stenting) can be successfully performed in patient with no or moderate disease by angiography. Plaque shift and incomplete stent expansion are important technical consideration when thinking about stenting the LM.

Because of concern about procedural risk \& long term durability, PCI has usually been restricted to patients who are poor candidates for surgery or have LMCA disease that is protected by a patent bypass graft to the left anterior descending or circumflex artery. The European guidelines for PCI stated that stenting for unprotected LMCA disease should only be considered in the absence of other revascularization options ${ }^{20}$. Likewise, the American guideline writing committee considered coronary artery bypass grafting as the gold standard for revascularization of lesions in the LMCA in patients eligible for CABG given the proven benefit in the long term ${ }^{21}$. However some cardiac interventionists feel that these guidelines do not take in to account the advances in stent technology and development of antiplatelet regimens which have minimized the incidence of acute \& sub acute stent thrombosis and restenosis ${ }^{22}$. It is necessary therefore to examine the evidence for LMCA stenting.

Balloon angioplasty of unprotected LMCA stenosis has been associated with varying degree of procedural success, but generally poor long term prognosis ${ }^{23-26}$. Previously reported unprotected LMCA stent procedures have been done in conditions of prohibitive surgical risk or in bailout situations ${ }^{27-32}$. Other investigators have reported primarily protected LMCA stenting ${ }^{33-35}$. The current study indicates that stenting of LMCA stenosis improves both the immediate procedural success and long term clinical outcomes compared with balloon angioplasty, in part because of the low sub-acute stent thrombosis rate using optimal stent implantation techniques ${ }^{36}$ \& new antiplatelet agent ${ }^{37}$. Most of the procedures in the current study were elective; all patient had normal LV function; and balloon inflations were intentionally kept short in duration. These facts may explain the high procedural success rate.

Our study shows excellent procedural success rate (100\%) with an excellent overall in-hospital survival rate (100\%). A total of 100 patients were selected non randomizedly considering the exclusion and inclusion criteria. All the lesions were predilated with balloon. All the patient were stented with drug eluting stent. Post dilatation was done in all cases with high pressure balloon.

Osteal and mid shaft lesions were managed as stenting in other main coronary arteries, but distal bifurcation lesions had some sorts of technical challenges.

In our study 30 patients had distal bifurcation lesion. Among these 30 cases 20 was managed with single stent strategy, out of this 20, four needed kissing balloon angioplasty. Rest 10 distal bifurcation lesions were managed with double stent strategy with a distribution of crush technique for 6 cases, $\mathrm{T}$ stenting for two cases, culotte stenting for two cases.

No patient developed any periprocedural major or minor adverse cardiac events like anginal chest pain, arrhythmias, 
cardiac arrest, cardiogenic shock, Q-wave MI, repeat revascularization and death during their hospital stay. So in this study our procedural success \& in-hospital survival rate was excellent (100\%). Main limitation of this study was lacking of IVUS to assess exact placement and optimal expansion of the stent which is especially important for distal bifurcation lesion to ensure adequate coverage of the lesion. Despite this limitation our study shows that stenting of unprotected LMCA stenosis is a safe and effective revascularization procedure in a carefully selected patient group with preserved LV function.

\section{Conclusion:}

This study result shows that despite the limited facility and financial limitations in Bangladesh, patients who underwent PCI in left main coronary artery had good inhospital outcomes, nearly similar to outcomes seen in studies conducted in other countries. Thus, PCI may be the preferred reperfusion strategy for the management of critical left main coronary artery intervention in the current Bangladesh setting.

Our future perspective is to establish the comparison of survival outcome in ULMCA stenting versus CABG in our patient population. Further study is also required to assess the long term outcome in ULMCA stenting.

\section{References:}

1. Stone P, Goldschlager N. Left main coronary artery disease: review and appraisal. Cordiovasc Med 1979; 4:165-177.

2. DeMots H, Rosch J, McAnulty J. Left main coronary artery disease. Cordiovasc Clin 1977; 8: 201-211.

3. Taylor H, Deumite N, Chaitman B, Davis K, Killip J, Rogers W. Asymptomatic left main coronary artery disease in the Coronary Artery Surgery Study (CASS) registry. Circulation 1989; 79:1171 -1179.

4. Cohen M, Gorlin R. Main left coronary artery disease: clinical experience from 1964-1974. Circulation 1975; 52: 275-285.

5. Yusuf S. Zucker D, Peduzzi P, Fisher LD, Takaro T, Kennedy JW, Davis K, Killip T, Passamani E, Norris R. Effect of coronary artery bypass graft surgery on survival: overview of 10-year results from randomised trials by the Coronary Artery Bypass Graft Surgery Trialists Collaboration. Lancet 1994; 344:1446.

6. Chaitman BR, Fisher LD, Bourassa MG, Davis K, Rogers WJ, Maynard C, Tyras DH, Berger RL, Judkins MP, Ringgvist I, Mock YB, Killip T. Effect of coronary bypass surgery on survival patterns in subsets of patients with left main coronary artery disease report of the Collaborative Study in Coronary Artery Surgery (CASS). Am J Cardiol 1981; 48: 765 -777.

7. Takaro T, Peduzzi P, Detre KM, Hultgren HN, Murphy ML, van der Bel-Kahn J, Thomsen J, Meadows WR. Survival in subgroups of patients with left main coronary artery disease:
Veterans Administration Cooperative Study of Surgery for Coronary Arterial Occlusive Disease. Circulation 1987; 66:14-27.

8. Caracciolo EA, Davis KB, Sopko G, Kaiser GC, Corley SD, Schaff H, Taylor HA, Chaitman BR. Comparison of surgical and medical group survival in patients with left main equivalent coronary artery disease: long-term CASS experience. Circulation 1995; 91.2335-2344.

9. Lopez JJ. Ho KK, Stoler RC; Percutaneous treatment of protected and unprotected left main coronary stenoses with new devices. immediate angiographic results and intermediateterm follow-up. J Am Coll Cardiol. 29 1997:345-352.

10. Laham RJ, Carrozza JP, Baim DS; Treatment of unprotected left main stenoses with Palmaz-Schatz stenting. Cathet Cardiovasc Diagn. 37 1996:77-80.

11. Colombo A, Gaglione A, Nakamura S, Finci L; ' Kissing” stents for bifurcational coronary lesion. Cathet Cardiovasc Diagn. 30 1993:327-330.

12. Macaya C, Alfonso F, Iniguez A, Goicolea J, Hernandez R, Zarco P; Stenting for elastic recoil during coronary angioplasty of the left main coronary artery. Am J Cardiol. 70 1992:105107.

13. Sathe S, Sebastian M, Vohra J, Valentine P; Bailout stenting for left main coronary artery occlusion following diagnostic angiography. Cathet Cardiovasc Diagn. 31 1994; 70-72.

14. Garcia-Robles JA, Garcia E, Rico M, Esteban E, Perez de Prado A, Delcan JL; Emergency coronary stenting for acute occlusive dissection of the left main coronary artery. Cathet Cardiovasc Diagn. 30 1993; 227-229.

15. Colombo A, Hall P, Nakamura S; Intracoronary stenting without anticoagulation accomplished with intravascular ultrasound guidance. Circulation. 91 1995: 1676-1688.

16. Schoemig A, Neumann FJ, Kastrati A; A randomized comparison of antiplatelet and anticoagulant therapy after the placement of coronary artery stents. N Engl J Med. 334 1996; 1084-1089.

17. Kalbfleisch H, Hort W. Quantitative study on the size of coronary artery supplying areas postmortem. Am Heart J 1977; 94: 183-188.

18. Macaya C, Alfonso F, Iniguez A, Goicolea J, Hernandez R, Zarco P. Stenting for elastic recoil during coronary angioplasty of the left main coronary artery. Am J Cardiol 1997; 70: 105-107.

19. Ku DN, Giddens DP, Zarins CK, Glagov S. Pulsatile flow and atherosclerosis in the atherosclerosis in the human carotid bifurcation. Positive correlation between plaque location and low oscillating shear stress. Arteriosclerosis 1985; 5: 293-302.

20. Silber S, Albertson P, Aviles FF, et al. Guidelines for PCI. The Task Force for PCI of the European Society of cardiology Eur Heart J 2005; 26:804-47.

21. Smith SC Jr, Feldman TE, Hirshfeld JW Jr, et al. ACC/AHA/ SCAI 2005 guideline update for PCI-summary article: A report of the American College of Cardiology/American Heart Association Task Force on practice guidelines (ACC/AHA/ 
SCAI writing committee to update the 2001 Guidelines for PCI) Circulation 2006; 113: 156-75.

22. Bottner RK, Klein LW. Do the current ACC/AHA guidelines correctly reflect the attitudes and utilization of PCI in patients with unprotected LM coronary Intervention? Catheter Cardiovasc Interv 2005; 64: 402-5.

23. Gruentzig AR, Senning A, Siegenthaler WE; Nonoperative dilatation of coronary artery stenosis. N Engl J Med. 301 1979: 61-67.

24. O’Keefe JH. Hartzler GO. Rutherford BD: Left main coronary angioplasty. early and late results of 127 acute and elective procedures . Am J Cardiol. 64 1989:144-147 .

25. Hartzler GO, Rutherford BD, McConohay DR, Johnson WL, Giorgi LV; "High-risk” percutaneous transluminal coronary angioplasty. Am J Cardiol. 6l 1988:33G-37G.

26. Eldar M, Schulhoff RN, Hertz I, Frankel R, Feld H. Shani J: Results of percutaneous transluminal coronary angioplasty of the left main coronary artery. Am J Cardiol. 68 1991: 255-256.

27. Lopez JJ. Ho KK, Stoler RC; Percutaneous treatment of protected and unprotected left main coronary stenoses with new devices. immediate angiographic results and intermediateterm follow-up. J Am Coll Cardiol. 29 1997:345-352.

28. Laham RJ, Carrozza JP, Baim DS; Treatment of unprotected left main stenoses with Palmaz-Schatz stenting. Cathet Cardiovasc Diagn. 37 1996:77-80.

29. Colombo A, Gaglione A, Nakamura S, Finci L; 'Kissing” stents for bifurcational coronary lesion. Cathet Cardiovasc Diagn. 30 1993:327-330.
30. Macaya C, Alfonso F, Iniguez A, Goicolea J, Hernandez R, Zarco $\mathrm{P}$; Stenting for elastic recoil during coronary angioplasty of the left main coronary artery. Am J Cardiol. 70 1992:105-107.

31. Sathe S, Sebastian M, Vohra J, Valentine P; Bailout stenting for left main coronary artery occlusion following diagnostic angiography. Cathet Cardiovasc Diagn. 31 1994; 70-72.

32. Garcia-Robles JA, Garcia E, Rico M, Esteban E, Perez de Prado A, Delcan JL; Emergency coronary stenting for acute occlusive dissection of the left main coronary artery. Cathet Cardiovasc Diagn. 30 1993; 227-229.

33. Tamura T, Nobuloshi M, Nosaka H; Palmaz-Schatz stenting in unprotected and protected left main coronary artery. immediate and follow-up result [abstract]. Circulation 94 (Suppl I) 1996: I-671.

34. Ellis SG, Moses J, White HJ; Contemporary percutaneous treatment of unprotected left main stenosis. a preliminary report of the ULTIMA (Unprotected Left Main Trunk Intervention Multicenter Assessment) registry [abstract]. Circulation. 94 (Suppl I) 1996:I-671.

35. Karam C, Jordan C, Fajadet J, Cassaneau B, Laurent JP, Marco $\mathrm{J}$; Six-month follow-up of unprotected left main coronary artery stenting [abstract]. Circulation 94 (Suppl I) 1996: I-627.

36. Colombo A, Hall P, Nakamura S; Intracoronary stenting without anticoagulation accomplished with intravascular ultrasound guidance. Circulation. 91 1995: 1676-1688.

37. Schoemig A, Neumann FJ, Kastrati A; A randomized comparison of antiplatelet and anticoagulant therapy after the placement of coronary artery stents. N Engl J Med. 334 1996; 1084-1089. 